\title{
NOTAS SOBRE A FORMAÇÃO DOCENTE - O SABER HISTÓRICO ESCOLAR NOS CURSOS DE FORMAÇÃO DE PROFESSORES DE HISTÓRIA
}

\author{
Mauro Cezar Coelho ${ }^{1}$ \\ Wilma de Nazaré Baía Coelho ${ }^{2}$
}

\begin{abstract}
RESUMO
O artigo aborda a formação docente, tendo em vista o espaço destinado ao saber escolar nos cursos de formação de professores de História. Para tanto, analisa os saberes que concorrem para a docência, cujo objetivo é demarcar as três competências que o professor deve compreender: o saber de referência, o saber sobre os processos de ensino-aprendizagem e o saber sobre os sujeitos com os quais interage. Nesse sentido, os autores consideram a legislação que reformula a perspectiva nos currículos da Educação Básica e os processos de formação de professores de História, de modo a perceber o lugar ocupado pelas discussões acerca das questões que interessam à Escola, seus agentes e o saber ali operado. Concluem que o saber docente não apenas cumpre função periférica nos processos de formação, como assumem um sentido meramente instrumental, o que denota uma fragilidade na formação docente em história na dimensão pedagógica.
\end{abstract}

Palavras-chave: Formação de professores. Saber histórico escolar. Saber historiográfico

\section{ABSTRACT \\ NOTES ON TEACHER TRAINING - HISTORICAL SCHOOL KNOWLEDGE IN HISTORY TEACHER TRAINING COURSES}

The article deals with teacher training, in view of the space destined to the school knowledge in the training courses of History teachers. To do so, it analyzes the knowledge that competes for teaching, whose objective is to demarcate the three competences that the teacher must understand: the knowledge of reference, the knowledge about the teaching-learning processes and the knowledge about the subjects with which it interacts. In this sense, the authors consider the legislation that reformulates the perspective in the curricula of Basic Education and the processes of formation of History teachers, in order to perceive the place occupied by the discussions about the issues that interest the School, its agents and the knowledge there operated. They conclude that teacher knowledge not only fulfills a peripheral function in the training processes, but also assumes a merely instrumental sense, which indicates a fragility in teacher training in history in the pedagogical dimension.

Key words: Teacher training. Knowing school history. To know historiographical.

\section{INTRODUÇÃO}

A formação docente tem estado em pauta nas últimas duas décadas. Em um intervalo de quatorze anos, as diretrizes para os cursos de formação docente sofreram duas alterações significativas. ${ }^{3}$ Ambas demarcam a especificidade da formação docente e seu caráter

\footnotetext{
1 Doutorado em História Social pela Universidade de São Paulo (2006). Professor Adjunto da Universidade Federal do Pará. E-mail: mauroccoelho@yahoo.com.br

2 Doutora em Educação/UFRN. Professora Associada III da UFPA. E-mail: wilmacoelho@yahoo.com.br

3 Desde 1996, as políticas de formação docente estão remetidas à Lei de Diretrizes e Bases da Educação, conforme BRASIL. Lei de Diretrizes e Bases da Educação Nacional. Lei N. 9.394, de 20 de dezembro de 1996.
} 
independente - por meio do que estabelecem as diretrizes, a licenciatura não compreende um complemento, nem, tampouco, a aquisição de uma competência adicional, de natureza técnica, que licencia para o exercício da docência. A formação de professores emerge da discussão como um espaço de desenvolvimento de um saber específico. Além disso, verificase a intensificação das discussões sobre formação continuada, as quais são acompanhadas por políticas voltadas para a qualificação de professores em diversos níveis. ${ }^{4}$ Estamos, pois, em um momento propício para a reflexão sobre a formação de professores.

Nesta oportunidade, pretendemos refletir sobre a formação docente, abordando o espaço destinado ao saber escolar nos cursos de formação de professores. Consideraremos, então, a formação oferecida pelas licenciaturas - neste caso, em História. Nossa intenção é perceber o lugar ocupado pelas discussões acerca das questões que interessam à Escola, seus agentes e o saber ali operado, tendo em vista os processos de formação de professores de História. A motivação para a reflexão que oferecemos emergiu das questões colocadas pela pesquisa em andamento. Ao debruçarmo-nos sobre os livros didáticos e percebemos o saber histórico operado por eles, consideramos pertinente investir na compreensão das formas pelos quais este mesmo saber é pensado nos cursos de formação docente. Trata-se de movimento inicial, ${ }^{5}$ o qual esperamos aprofundar no futuro.

A reflexão está organizada em dois momentos. No primeiro deles, nos ocupamos com os saberes que concorrem para a docência em História. Nosso objetivo é demarcar as três competências que o professor, qualquer professor, deve compreender: o saber de referência, o saber sobre os processos de ensino-aprendizagem e sobre os sujeitos com os quais interage e conformam o fim último de sua função social e política - o aluno. No segundo momento, apresentamos um ensaio de quantificação do espaço dispensado a cada um destes domínios

Diário Oficial da União, Brasília, DF, 23 de dezembro de 1996. Nesse período, o Conselho Nacional de Educação elaborou duas reformulações importantes. A primeira, consubstanciada em dois instrumentos: Resolução CNE/CP N. 01, de 18 de fevereiro de 2002, instituindo as diretrizes para os cursos de formação de professores. E Resolução CNE/CP N. 02, de 19 de fevereiro de 2002, definindo a carga horária para os mesmos cursos. A segunda, alterando as duas resoluções anteriores, conforme Resolução CNE/CP N. 02, de 01 de julho de 2015, propondo novas diretrizes curriculares para os cursos de formação de professores.

${ }^{4}$ Por intermédio da Secretaria de Educação Continuada, Alfabetização, Diversidade e Inclusão - SECADI/MEC, criada pelo Decreto $\mathrm{n}^{\circ}$ 5.159, de 28 de Julho de 2004, um conjunto de políticas públicas voltaram-se para a formação docente, com vistas, especialmente, ao combate às desigualdades educacionais em diferentes âmbitos, com foco privilegiado em ações de Educação Especial, Educação para as Relações Étnico-Raciais, Educação do Campo, Educação Escolar Indígena, Educação Quilombola, Educação em Direitos Humanos, Educação Inclusiva, Gênero e Diversidade Sexual, Combate à Violência, Educação Ambiental, Educação de Jovens e Adultos. Em outra perspectiva de formação, o Ministério da Educação implantou o Plano Nacional de Formação de Professores da Educação Básica - PARFOR, com o propósito fundamental de formação continuada de professores.

5 Mauro Cezar Coelho apresentou os dados desta pesquisa no XIII Encontro Estadual de História da ANPUH-RS: Ensino, Direitos e Democracia, sob o título A Escola e as Licenciaturas em História: discutindo as Diretrizes Curriculares para a Educação Básica (qual seu lugar nos cursos de formação de professores de História?). 
nos cursos de licenciatura em História. Nossa intenção é, simplesmente, apontar o investimento feito na formação das três competências fundamentais da docência em cursos de formação de historiadores. Neste último momento, que fique claro, não avançamos em análises que considerem outras variáveis que não a carga horária dos cursos. Pretendemos, pois, tão somente apontar algumas notas sobre as Licenciaturas em História.

\section{LICENCIATURA EM HISTÓRIA: SABER HISTORIOGRÁFICO E SABER ESCOLAR NA FORMAÇÃO DOCENTE ${ }^{6}$}

Refletir sobre os processos de formação de professores de História exige ter em conta a participação da Escola nos procedimentos de construção da memória e da consciência histórica para a comunidade escolar. Por anos, a Escola protagonizou os processos de delineamento da memória histórica, principalmente no que tange à vulgarização de narrativa sobre a formação do Brasil. Protagonismo não quer dizer, evidentemente, condução solitária. Um conjunto de expressões culturais, como a música, a literatura e dramaturgia, foi pródigo em oferecer versões sobre a construção do país e sobre a índole de sua gente. Mas, a Escola vem se conformando como a instância responsável por dois aspectos relacionados à sua função social: o encaminhamento de um processo formativo (voltado para a iniciação e o desenvolvimento do pensamento formal) e a socialização de parâmetros éticos e morais, estabelecidos pela sociedade. Logo, a Escola, diferentemente daquelas expressões culturais, está vinculada a um projeto que é tanto político quanto social, o qual se expressa nos instrumentos regulatórios da Educação Básica. Em função do exposto, no que concerne à memória história, à Escola importa menos o conteúdo da versão do que sua representatividade social e política, de modo que a História seja percebida e incorporada em acordo com sua função social: suporte para o desenvolvimento cognitivo e parâmetro ético e moral dos alunos.

Diante disso, ainda que a Escola não usufrua mais do protagonismo já experimentado na lida com a memória, posto que compartilha, hoje, com diversos outros suportes, como as mídias audiovisuais disponibilizadas pela rede mundial de computadores, jogos eletrônicos, revistas de circulação nacional especialmente ocupadas com a temática histórica, ela se mantém como instância importante nos processos de formação da memória histórica. A Escola se mantém, ainda (a despeito das ameaças em contrário) como o espaço no qual a memória pode (e deve) ser criticada. Além disso, para muitos dos cidadãos, alunos da

\footnotetext{
${ }^{6}$ As considerações que seguem foram elaboradas por Mauro Cezar Coelho e Wilma de Nazaré Baía Coelho apresentadas em artigo publicado em 2013. COELHO Wilma de Nazaré Baía; COELHO, Mauro Cezar (2014).
} 
Educação Básica, ela se mantém como a única instituição na qual se estabelece uma abordagem sistemática com a memória histórica, particularmente no que se refere à conformação da nacionalidade. É nela que uma narrativa acerca da construção do Brasil é tornada conhecida, por meio da apropriação feita pela mesma Escola a partir do saber historiográfico, das formulações da literatura didática e do saber docente.

Assumimos, por conseguinte, que o saber escolar acerca do passado, conformado em memória histórica, é um saber singular. Mesmo reconhecendo as remissões que o vinculam ao saber historiográfico - posto tratar-se de conhecimento histórico - entendemos ser ele um saber específico. O saber histórico escolar incorpora o saber historiográfico, mas não é definido por ele. Na Escola, menos que compreender o passado, o saber histórico está remetido aos subsídios que oferece à formação escolar: o incentivo ao amadurecimento cognitivo e à apropriação e ao desenvolvimento do pensamento formal, a partir do contato com o saber disciplinar. Nesse sentido, as abordagens sobre o passado conformam um empreendimento tão amplo quanto complexo que visa, entre outros propósitos, a apropriação de competências e habilidades que tornem o estudante capaz de exercer a análise e a crítica da memória.

Decorre daí que o aprendizado do saber historiográfico constitui uma das balizas da atuação do professor de História da Educação Básica, mas não a esgota. O saber histórico escolar sintetiza aquelas balizas, indicando o lugar ocupado por cada uma das competências docentes. ${ }^{7}$ Importa, então, refletir sobre esse saber.

Ana Maria Monteiro é referência acerca do saber histórico escolar. Em obra de leitura obrigatória por todos aqueles que tem no ensino de história a razão do ofício, a autora destaca o fator estruturante do saber escolar - a perspectiva educativa. ${ }^{8} \mathrm{O}$ caráter educativo empresta não somente forma aos saberes operados pela escola, mas define-os, atribuindo sentido aos saberes disciplinares. Ou seja, os saberes de referência estão a serviço de uma função pedagógica, a qual determina seus lugares, importâncias e as relações que estabelecem entre si. A função pedagógica, a perspectiva educativa, compreende dois fatores estruturantes daquele saber: a axiologização (os valores que permeiam a formação oferecida) e a didatização (as transformações a que o saber de referência é submetido com vistas aos propósitos educativos). ${ }^{9}$

\footnotetext{
${ }^{7}$ PERRENOUD, Philippe (2000)

${ }^{8}$ MONTEIRO, Ana Maria Ferreira da Costa (2007).

${ }^{9}$ Idem, p. 81-111.
} 
A consideração da especificidade do saber histórico escolar ${ }^{10}$ remete à discussão sobre o seu lugar nos cursos de formação de professores de História - que espaços as dimensões que o conformam ocupam nos cursos de Licenciatura? Com esse objetivo, abordaremos o enfoque dispensado a dois aspectos do saber histórico escolar, o domínio historiográfico e o domínio da docência - relativo aos demais fatores estruturantes desse saber.

Para este texto, analisamos as trajetórias curriculares de treze cursos de licenciatura em História. Os cursos foram selecionados considerando, em primeiro lugar, a disponibilização do Projeto Político Pedagógico por meio da rede mundial de computadores. Optamos por trabalhar apenas com os dados de cursos oferecidos por universidades federais, com vistas a garantir maior uniformidade aos dados e maior representatividade no universo pesquisado razão pela qual consideramos, dentre as universidades federais, as universidades dos estados da União e não instituições de cidades ou regiões. Nossa intenção foi, também, garantir o acesso a um projeto político pedagógico operado por um corpo docente mais experimentado e a um curso consolidado. Diante de tais critérios, o universo resultante congregou treze cursos, assim distribuídos: um curso da região Centro-Oeste, três cursos da região Norte, quatro cursos da região Nordeste, três cursos da região Sudeste e dois cursos da região Sul.

Ao analisarmos os percursos curriculares, consideramos os aspectos comuns, conforme o estabelecido pela legislação vigente, ${ }^{11}$ de forma a identificar aspectos comuns e destacar as especificidades. Conforme estabelece tal legislação, os cursos de graduação na modalidade licenciatura devem ter carga horária mínima de 2.800 horas, das quais 1.000 horas assim distribuídas: 200 horas de atividades acadêmico-científico-culturais, 400 horas de Estágio Supervisionado e 400 horas de Prática como Componente Curricular. Todos os cursos analisados destinavam mil horas para as atividades exigidas, as quais não foram consideradas na análise que oferecemos.

Conforme dá conta a mesma legislação, as atividades acadêmico-científico-culturais têm por objetivo possibilitar aos alunos a ampliação de sua experiência de formação, por meio da escolha de atividades que possibilitem o estabelecimento de nexos com o curso escolhido. A prática como componente curricular e o estágio supervisionado são, também, espaços de formação. A primeira pretende facultar aos futuros professores o trato com o cotidiano escolar, de modo a familiarizá-lo com as questões vivenciadas pela escola. Oferecida desde o primeiro ano de formação, ela pressupõe a incorporação das questões experimentadas pelos

\footnotetext{
${ }^{10}$ VALDEMARIN, Vera Teresa (1998); CARDOSO, Oldimar Pontes (2007).

${ }^{11}$ Referimo-nos à Resolução CNE/CP N. 01, de 18 de fevereiro de 2002, instituindo as diretrizes para os cursos de formação de professores e Resolução CNE/CP N. 02, de 19 de fevereiro de 2002, instituindo a carga horária para os mesmos cursos (ambas citadas, anteriormente).
} 
alunos nas disciplinas de cunho teórico-científico. O estágio supervisionado é um espaço de formação, mas também de exercício de saberes adquiridos nas demais disciplinas. Ao contrário do que ocorre com a prática como componente curricular, nele se espera que o futuro professor exercite (e desenvolva) as competências e habilidades da docência apreendidas ao longo da formação.

Tais atividades formativas são exigidas pela legislação. Elas não compreendem qualquer inflexão da parte dos corpos docentes dos cursos de licenciatura, no sentido de promove-las. Elas certamente incorporam a discussão acumulada acerca dos processos de formação docente, especialmente a importância da experiência e da familiarização com os problemas da Escola. No entanto, não conformam uma opção dos projetos políticos pedagógicos. Diante disso, não as consideramos para a análise aqui proposta. Nos concentramos, como se pode deduzir, nas demais disciplinas, aquelas sobre as quais os corpos docentes dos cursos analisados tiveram autonomia para deliberar. Nossa intenção foi perceber, por meio delas, o espaço destinado à formação do professor, para além do que exige a legislação - a qual encaminha os aspectos práticos do desenvolvimento das competências dos docentes.

Em relação a estas atividades curriculares, após a consideração dos percursos dos treze cursos, procedemos a uma outra delimitação, com vistas a uniformização dos dados. Consideramos para efeito de análise apenas as atividades obrigatórias - aquelas que todos os futuros professores deveriam, necessariamente, cursar, a fim de concluir o processo formativo. Esse conjunto foi categorizado em dois grupos de atividade - as voltadas para o Saber Historiográfico e aquelas ocupadas com o Saber da Docência. Trata-se, evidentemente, de uma categorização com vistas a perceber diferenças no escopo das atividades. Está claro para nós que o saber de referência conforma o saber docente e é dele inseparável. No entanto, para efeito de análise e em conformidade com as discussões acerca do saber histórico escolar, buscamos perceber o lugar dos demais saberes, além daquele referente, nos processos de formação de professores de História. Iniciemos pelo saber historiográfico.

Denominamos de Saber Historiográfico o conjunto de atividades ocupadas com o conhecimento histórico. Consideramos, neste caso, as atividades que buscam dar conta da origem e do percurso da Disciplina, além de seus fundamentos teóricos e metodológicos. Fazem parte do escopo, ainda, as atividades voltadas para a familiarização com períodos ou temas, aquelas que estabelecem diálogos com outras disciplinas e as responsáveis pelo tratamento de aspectos conformadores do ofício. Atividades curriculares relativas à introdução aos estudos históricos (como Teoria e Metodologia), a abordagens de períodos 
(como Antiguidade, Idade Média, Idade Moderna, Idade Contemporânea), de espaços (Brasil, América, Região) ou de temas (como Economia, Ideias Políticas, África e Cultura AfroBrasileira, História Indígena e disciplinas temáticas), assim como aquelas voltadas para o diálogo com outras disciplinas (Antropologia, Filosofia, Geografia e Sociologia) compreendem esse conjunto.

Consideramos que tais atividades cumprem uma função importante no processo de reconhecimento e de reprodução dos modos de construção do Saber Historiográfico. Por meio delas, os cursos pretendem, em conformidade com o que afirma a discussão acerca da produção do saber histórico, ${ }^{12}$ desenvolver nos futuros professores o trato com três instâncias do ofício: a produção historiográfica, as fontes e os aportes teóricos. Assim, o Saber Historiográfico operado e facultado pelos processos formativos analisados pretende dar conta do conhecimento acumulado que conforma e ao mesmo tempo institui o saber de referência. A produção historiográfica cumpre função estruturante, posto permitir que os futuros professores de História se familiarizem tanto com as formas assumidas pelas narrativas produzidas pelos historiadores quanto com os temas, os problemas, os objetos e os percalços enfrentados pelas análises. O saber ora em discussão pretende, também, iniciar o aluno da licenciatura em História nos processos que transformam os documentos em fontes e como estas são objeto de um conjunto controlado de processos que permitem o engendramento de análises e de modelos de explicação/interpretação do passado. ${ }^{13}$ Em seguida, o Saber da Docência.

No que se refere aos saberes da docência, não pudemos adotar a mesma perspectiva em relação ao saber de referência. Isto se deve ao fato de que, ao contrário do ocorrido com os saberes de referência, os saberes da docência não conformam apenas uma área do conhecimento. Eles se constituem por meio de uma perspectiva e de uma postura interdisciplinar. ${ }^{14}$ Ou seja, não apenas eles exigem, nos processos de formação, o recurso de várias áreas disciplinares, como demandam, na Escola, uma atitude de pensamento pautada na conjugação dos vários fatores relacionados à condução da vida escolar. ${ }^{15}$

Tal fator estruturante dos saberes da docência levou-nos a privilegiar categorias que

\footnotetext{
12 Destacamos aqui, duas obras: FURET, Francois. A oficina da história. Lisboa: Gradiva, [s.d.], p. 7-37 e CERTEAU, Michel de. A operação histórica. In: LE GOFF, Jacques; NORA, Pierre (dir.) (1984. p. 18-48).

${ }^{13}$ Sobre tais questões, limitar-nos-emos a indicar duas contribuições de um mesmo autor: LE GOFF, Jacques. História. Documento/Monumento. In: História e Memória. Campinas: Editora da UNICAMP, 1996. p. 17-166 e 535-549.

14 GAUTHIER, Clermont et al. (2006); TARDIF, Maurice. (2002); BORGES, Cecília (2001).

15 FAZENDA, Ivani (1992); BOCHNIAK, Regina (1992); FRAGA, Dinora; SILVEIRA, Nádia Geisa (1995); FAZENDA, Ivani (1999).
} 
expressassem e incorporassem a diversidade de perspectivas e posturas presentes nas atividades curriculares voltadas para a formação das competências e habilidades que se espera ser de domínio do professor. Inspirados em formulação tornada recorrente a partir das reflexões de Flávia Heloísa Caimi, segundo a qual para ensinar História a alguém é preciso saber de História, saber de Ensinar e saber de Alguém, ${ }^{16}$ assumimos como categorias observáveis do Saber da Docência, as atividades curriculares voltadas para os processos de ensino e para o conhecimento sobre os alunos. Por meio de tais categorias, esperamos atentar para duas dimensões da atuação docente, as quais, espera-se, estejam contempladas nos processos de formação de professores de História.

Em primeiro lugar, a compreensão dos processos de ensino e aprendizagem como um domínio que requer especialização e aprofundamento. Parte-se do princípio de que, para os processos de ensino e aprendizagem, o saber de referência não esgota as operações possíveis a serem concretizadas pelo professor. Tampouco se considera que estas últimas são facultadas a partir do domínio de um conjunto de técnicas de "ensinagem", de modo a garantir a transposição do saber de referência em saber escolar. Conforme aponta extensa literatura, os processos de ensino e aprendizagem compreendem o domínio da didática, da epistemologia da aprendizagem, da função social do conhecimento e da Escola, dos projetos em disputa, expressos no currículo escolar, e dos sentidos dado à formação pela sociedade envolvente. ${ }^{17}$ Sem isso, se corre o risco de assumir o ensino de dado saber como um fim em si mesmo e da Escola como uma instituição livre das interferências da sociedade que a constitui.

Em segundo lugar, o entendimento de que os processos de ensino e aprendizagem não se dão por sobre uma tábula rasa, a qual simplesmente absorve o que lhe é apresentado de modo integral e uniforme. Entender o sujeito do processo da aprendizagem e do ensino, o aluno, é fundamental. Nesse sentido, os estudos sobre a psicologia da aprendizagem e a psicologia da infância e da adolescência têm sido essenciais para a compreensão das operações realizadas na apropriação do conhecimento. ${ }^{18}$ Entender as operações realizadas por tais sujeitos assume um papel determinante nas escolhas feitas pelos docentes acerca de quando e de como abordam isto ou aquilo.

E não só. Se apropriar de estruturas do conhecimento que permitam problematizar como pensam é fundamental, mas saber quem são também. Os alunos da Educação Básica são

\footnotetext{
${ }^{16}$ CAIMI, Flávia Eloisa ( 2006); idem (2008).

${ }^{17}$ WERNECK, Vera Rudge (2006).

18 PIAGET, Jean (1980); PIAGET, Jean; INHELDER, Barbel (1994); ALMEIDA, José Luis Vieira; TREVISO (2014); VYGOTSKY, Liev Semiónovitch (2008).
} 
agentes sociais inseridos em condições que afetam o modo pelo qual concebem a Escola, a Educação e a forma como delineiam sua relação com o conhecimento. Além disso, a infância, a adolescência e a juventude conformam estágios da vida experimentados historicamente. $\mathrm{Ou}$ seja, em que pese a importância dos estudos da psicologia para a compreensão das formas de desenvolvimento cognitivo, tais agentes são crianças e jovens que vivem suas experiências no tempo - daí que percebê-los na sua especificidade compreendendo os significados que as fases etárias assumem no mundo no qual estão inseridos é parte essencial do processo de conhece-los. ${ }^{19}$ Daí atentarmos para a existência de atividades curriculares voltados para a História da Infância e da Adolescência ou que problematizassem a clientela de escolas públicas - destino da imensa maioria dos egressos dos cursos de formação de professores de História.

Em síntese, a análise empreendida buscou distinguir, nas grades dos cursos selecionados, os saberes voltados para a formação historiográfica e aqueles comprometidos com a docência. Deixou de considerar nesse conjunto, as atividades curriculares obrigatórias, estabelecidas pela legislação vigente, com vistas à formação do professor. Nosso objetivo foi perceber o dimensionamento dado pelos docentes dos cursos ao saber histórico escolar nos processos de formação do professor de História. Vejamos, em seguida, como se conformam os percursos curriculares de formação que analisamos.

\section{PERCURSOS DE FORMAÇÃO - SABER HISTÓRICO E SABER DOCENTE}

Nesta seção, apresentaremos e discutiremos os dados coletados. Antes, porém, uma consideração acerca da identificação das instituições selecionadas. Não nomearemos as instituições. Nos referiremos a elas por um número e pela sigla da região na qual se encontra (assim, 1S identifica uma das duas instituições da região Sul, por exemplo). Por meio desse recurso, buscamos privilegiar as questões aqui colocadas, sem sugerir que são exclusivas das instituições com as quais trabalhamos. Estas são referências nos estados da união onde se encontram, de modo que boa parte do que pontuam é apropriado pelas instituições circundantes.

Também importa destacar o critério adotado por nós para sopesarmos o espaço destinado a cada uma das dimensões da docência nos percursos curriculares. Consideramos, aqui, a legislação em vigor, a qual estipula em horas o tempo destinado aos componentes

\footnotetext{
${ }^{19}$ Destacamos os seguintes estudos. KEHL, Maria Rita (1999); CARDOZA, Isabela Fonseca (2003); CUNHA, Olívia Maria Gomes da. Bonde do mal: notas sobre território, cor, violência e juventude numa favela do subúrbio carioca. In: REZENDE, Claudia Barcellos; MAGGIE, Yvonne (2001. p. 83-153); DAYRELL, Juarez (2002); LIMA, Ari (2002); MAGRO, Viviane Melo de Mendonça (2002); GARBIN, Elisabete Maria (2003).
} 
curriculares responsáveis pelo trato com as competências dos futuros professores nos percursos das licenciaturas. Diante disso, optamos por considerar o tempo investido pelos cursos em cada um dos saberes referidos anteriormente.

Antes, porém, vejamos como se estrutura a distribuição do tempo em todos os cursos.

\begin{tabular}{|c|c|c|c|c|c|}
\hline \multirow[b]{3}{*}{ Instituição } & \multicolumn{5}{|c|}{$\begin{array}{l}\text { DistRIBUIÇÃo DA CARGA HORÁRIA POR ATIVIDADES CURRICULARES } \\
\text { (em horas) }\end{array}$} \\
\hline & \multicolumn{5}{|c|}{ Atividades Curriculares } \\
\hline & Total & $\begin{array}{c}\text { Estágio } \\
\text { Supervisionado }\end{array}$ & $\begin{array}{c}\text { Prática } \\
\text { c/Componente } \\
\text { Curricular }\end{array}$ & $\begin{array}{l}\text { Teórico } \\
\text { Científicas }\end{array}$ & $\begin{array}{c}\text { Atividades } \\
\text { Acadêmico- } \\
\text { Científico- } \\
\text { Culturais }\end{array}$ \\
\hline $1 \mathrm{CO}$ & 3268 & 400 & 0 & 2668 & 200 \\
\hline $1 \mathrm{NE}$ & 2800 & 400 & 400 & 1800 & 200 \\
\hline $2 \mathrm{NE}$ & 2985 & 405 & 0 & 2370 & 210 \\
\hline $3 \mathrm{NE}$ & 2830 & 405 & 0 & 2145 & 280 \\
\hline $4 \mathrm{NE}$ & 2865 & 405 & 0 & 2250 & 210 \\
\hline $1 \mathrm{~N}$ & 2865 & 420 & 420 & 1815 & 210 \\
\hline $2 \mathrm{~N}$ & 2860 & 500 & 300 & 1860 & 200 \\
\hline $3 \mathrm{~N}$ & 3420 & 420 & 420 & 2370 & 210 \\
\hline $1 \mathrm{SE}$ & 3300 & 400 & 525 & 2175 & 200 \\
\hline $2 \mathrm{SE}$ & 2805 & 405 & 360 & 1830 & 210 \\
\hline $3 \mathrm{SE}$ & 3240 & 400 & 450 & 2190 & 200 \\
\hline $1 \mathrm{~S}$ & 3366 & 486 & 144 & 2496 & 240 \\
\hline $2 \mathrm{~S}$ & 2880 & 450 & 0 & 2430 & 0 \\
\hline
\end{tabular}

Fonte: quadro elaborado pelos autores, 2016

Como se pode notar, todos os cursos cumprem com o mínimo estabelecido para a carga horária dos cursos de licenciatura: 2800 horas. No entanto, nem todos cumprem com todos os fundamentos. Percebemos que em algumas instituições, a Prática como Componente Curricular é associada a outras atividades curriculares, desempenhando uma função complementar àquelas atividades. ${ }^{20}$ Nestes casos, não ficam estabelecidas duas premissas relativas à Prática como Componente Curricular. Em primeiro lugar, seu lugar como campo de aprendizagem e de prática das competências relativas à docência. Em segundo lugar, sua condição de espaço no qual se vivencia e se discutem, a partir da

${ }^{20}$ Nos cursos em que verificamos a ocorrência desta prática, as quatrocentas horas destinadas pela legislação à Prática como Componente Curricular são agregadas às atividades teórico-científicas. Como exemplo, podemos considerar uma atividade curricular recorrente nos cursos analisados, a História do Brasil Colonial (que recebe denominações diversas a depender do currículo, independentemente do fato de tratar, via de regra, da experiência da Conquista e Colonização). Se a carga horária teórica da atividade perfaz 68 horas, ela é acrescida de mais algumas horas (doze, quatorze ou dezessete), as quais são atribuídas à Prática como Componente Curricular. 
experiência, os problemas e as situações apresentadas pelo ambiente escolar.

Isto posto, consideremos a tabela. Fica claro que as atividades teórico-científicas ocupam a maior parte da carga horária dos cursos e, por conseguinte, concentram o escopo daquilo que os corpos docentes das instituições compreendem como necessário à formação. Para que se tenha uma noção do quanto representam as atividades Teórico-Científicas e de modo a adicionar mais um fator a justificar nossa opção por concentrar nelas a análise que propomos, apresentamos a mesma tabela, desta feita indicando o percentual de tempo destinado a cada uma das atividades curriculares.

\begin{tabular}{|c|c|c|c|c|c|}
\hline \multirow[b]{3}{*}{ Instituição } & \multicolumn{4}{|c|}{ DistRIBUIÇÃO DA CARGA HORÁRIA POR ATIVIDADES CURRICULARES } & \multirow[b]{3}{*}{$\begin{array}{c}\text { Atividades } \\
\text { Acadêmico- } \\
\text { Científico- } \\
\text { Culturais }\end{array}$} \\
\hline & \multirow[b]{2}{*}{$\begin{array}{l}\text { Total } \\
\text { (horas) }\end{array}$} & \multicolumn{3}{|c|}{$\begin{array}{c}\text { Atividades Curriculares } \\
\qquad(\%)\end{array}$} & \\
\hline & & $\begin{array}{c}\text { Estágio } \\
\text { Supervisionado }\end{array}$ & $\begin{array}{c}\text { Prática } \\
\text { c/Componente } \\
\text { Curricular }\end{array}$ & $\begin{array}{c}\text { Teórico } \\
\text { Científicas }\end{array}$ & \\
\hline $1 \mathrm{CO}$ & 3268 & 12,24 & 0 & 81,64 & 6,12 \\
\hline $1 \mathrm{NE}$ & 2800 & 14,29 & 14,29 & 64,28 & 7,14 \\
\hline $2 \mathrm{NE}$ & 2985 & 13,57 & 0 & 79,39 & 7,04 \\
\hline $3 \mathrm{NE}$ & 2830 & 14,32 & 0 & 75,79 & 9,89 \\
\hline $4 \mathrm{NE}$ & 2865 & 14,14 & 0 & 78,53 & 7,33 \\
\hline $1 \mathrm{~N}$ & 2865 & 14,66 & 14,66 & 63,36 & 7,32 \\
\hline $2 \mathrm{~N}$ & 2860 & 17,48 & 10,49 & 65,03 & 6,99 \\
\hline $3 \mathrm{~N}$ & 3420 & 12,28 & 12,28 & 69,30 & 6,14 \\
\hline $1 \mathrm{SE}$ & 3300 & 12,12 & 15,91 & 65,91 & 6,06 \\
\hline $2 \mathrm{SE}$ & 2805 & 14,44 & 12,83 & 65,24 & 7,49 \\
\hline $3 \mathrm{SE}$ & 3240 & 12,35 & 13,89 & 67,59 & 6,17 \\
\hline $1 \mathrm{~S}$ & 3366 & 14,44 & 4,28 & 74,15 & 7,13 \\
\hline $2 \mathrm{~S}$ & 2880 & 15,63 & 0 & 84,38 & 0 \\
\hline
\end{tabular}

Fonte: quadro elaborado pelos autores, 2016

Claro está, então, que os cursos analisados destinam, pelo menos, três quintos da carga horária para os componentes teórico-científicos. Logo, cabe considerar que saberes tais componentes privilegiam, ao demandarem tamanho espaço do tempo de formação do futuro professor de História. Nos deparamos, todavia, com um outro fator: parte da carga horária teórico-científica é de livre escolha dos alunos; ou seja, um percentual do tempo de formação é definido pelos alunos, em acordo com as ofertas das instituições nas quais estão inseridos. Vejamos como tal carga horária é distribuída nas instituições analisadas. 


\begin{tabular}{|c|c|c|c|c|}
\hline & Distinç & $\begin{array}{r}\text { CARGa HoR } \\
\text { OBRIGAT }\end{array}$ & $\begin{array}{l}\text { ATIVIDADES T } \\
\text { LIVRE ESCOLH } \\
\text { 0) }\end{array}$ & IÍFICAS \\
\hline \multirow[b]{2}{*}{ Instituição } & \multicolumn{4}{|c|}{ Atividades Curriculares } \\
\hline & $\begin{array}{c}\text { Carga } \\
\text { Horária } \\
\text { Total }\end{array}$ & $\begin{array}{c}\text { Teórico } \\
\text { Científicas } \\
(\%)\end{array}$ & $\begin{array}{c}\text { Obrigatórias } \\
(\%)\end{array}$ & $\begin{array}{c}\text { Livre Escolha } \\
(\%)\end{array}$ \\
\hline $1 \mathrm{CO}$ & 3268 & 81,64 & 81,64 & 0 \\
\hline $1 \mathrm{NE}$ & 2800 & 64,28 & 57,14 & 7,14 \\
\hline $2 \mathrm{NE}$ & 2985 & 79,39 & 67,33 & 12,06 \\
\hline $3 \mathrm{NE}$ & 2830 & 75,79 & 71,55 & 4,24 \\
\hline $4 \mathrm{NE}$ & 2865 & 78,53 & 72,25 & 6,28 \\
\hline $1 \mathrm{~N}$ & 2865 & 63,36 & 54,98 & 8,38 \\
\hline $2 \mathrm{~N}$ & 2860 & 65,03 & 65,03 & 0 \\
\hline $3 \mathrm{~N}$ & 3420 & 69,30 & 65,79 & 3,51 \\
\hline $1 \mathrm{SE}$ & 3300 & 65,91 & 51,36 & 14,55 \\
\hline $2 \mathrm{SE}$ & 2805 & 65,24 & 51,34 & 13,90 \\
\hline $3 \mathrm{SE}$ & 3240 & 67,59 & 50,92 & 16,67 \\
\hline $1 \mathrm{~S}$ & 3366 & 74,15 & 62,03 & 12,12 \\
\hline $2 \mathrm{~S}$ & 2880 & 84,38 & 63,54 & 20,83 \\
\hline
\end{tabular}

Fonte: quadro elaborado pelos autores, 2016

Como se vê, o grau de inserção e controle do percurso curricular dos futuros professores de História varia significativamente. A carga horária obrigatória compreende pelo menos cinquenta por cento da carga horária total. Não nos deteremos aqui na pertinência ou não da autonomia discente, nos cursos de licenciatura, sobre parte de sua formação. No entanto, não se pode esquecer um fator estruturante: no Brasil, professores concretizam um direito público, cujos detentores são crianças e adolescentes, para quem o modo como se dá o acesso e o exercício desse mesmo direito tem desdobramentos determinantes em sua trajetória de vida; o fato de a Educação constituir um direito do aluno deve servir de critério para definir o quanto da formação (voltada para a concretização de um direito que é de outro) pode refletir interesses que não os dos sujeitos dos direitos.

De todo modo, a consideração do percurso obrigatório para nós é fundamental, pois por meio dele podemos sopesar o que os percursos curriculares selecionados definem como a formação do futuro professor de História, desde a perspectiva dos professores formadores, nas universidades. Detenhamo-nos, então, nestes percursos obrigatórios. Em relação a eles, tabulamos, inicialmente, aquilo que concerne ao Saber Historiográfico e ao Saber Docente. Esclarecemos: tendo as atividades teórico-científicas como escopo da análise, observamos, nos percursos obrigatórios, aquelas voltadas para os domínios historiográficos e para os 
domínios da docência, em acordo com as distinções já estabelecidas páginas atrás.

Atentemos para o quadro a seguir. Ele está organizado de modo a apresentar os seguintes dados, tendo a carga horária total dos cursos como parâmetro: o percentual de atividades obrigatórias e, em relação a elas, o quanto é dispendido para cada um dos domínios referidos.

\begin{tabular}{|c|c|c|c|c|}
\hline \multirow[b]{3}{*}{ Instituição } & \multicolumn{4}{|c|}{$\begin{array}{c}\text { ATIVIDADES TEÓRICO-CIENTÍFICAS OBRIGATÓRIAS } \\
\text { SABER HistorIOGRÁFICO E SABER DOCENTE } \\
(\%)\end{array}$} \\
\hline & \multicolumn{4}{|c|}{ Atividades Curriculares } \\
\hline & $\begin{array}{l}\text { Carga } \\
\text { Horária } \\
\text { Total }\end{array}$ & $\begin{array}{l}\text { Teórico } \\
\text { Científicas } \\
\text { Obrigatória } \\
\quad(\%)\end{array}$ & $\begin{array}{c}\text { Saber } \\
\text { Historiográfico } \\
(\%)\end{array}$ & $\begin{array}{c}\text { Saber Docente } \\
(\%)\end{array}$ \\
\hline $1 \mathrm{CO}$ & 3268 & 81,63 & 59,12 & 22,52 \\
\hline $1 \mathrm{NE}$ & 2800 & 57,14 & 48,00 & 9,14 \\
\hline $2 \mathrm{NE}$ & 2985 & 67,33 & 55,28 & 12,06 \\
\hline $3 \mathrm{NE}$ & 2830 & 71,55 & 47,70 & 23,85 \\
\hline $4 \mathrm{NE}$ & 2865 & 72,25 & 61,78 & 10,47 \\
\hline $1 \mathrm{~N}$ & 2865 & 54,98 & 48,17 & 6,81 \\
\hline $2 \mathrm{~N}$ & 2860 & 65,03 & 58,74 & 6,29 \\
\hline $3 \mathrm{~N}$ & 3420 & 65,79 & 57,02 & 8,77 \\
\hline $1 \mathrm{SE}$ & 3300 & 51,36 & 40,00 & 11,36 \\
\hline $2 \mathrm{SE}$ & 2805 & 51,34 & 42,78 & 8,56 \\
\hline $3 \mathrm{SE}$ & 3240 & 50,92 & 50,00 & 0,92 \\
\hline $1 \mathrm{~S}$ & 3366 & 62,03 & 45,99 & 16,04 \\
\hline $1 \mathrm{~S}$ & 2880 & 63,54 & 54,17 & 9,37 \\
\hline
\end{tabular}

Fonte: quadro elaborado pelos autores, 2016

O primeiro recorte acerca dos conteúdos teórico-científicos obrigatórios deixa claro a preponderância do Saber Historiográfico em relação aos saberes da docência. As atividades curriculares voltadas para a introdução e desenvolvimento de competências comprometidas com a problematização do passado se sobrepõem às demais, considerando, inclusive, aquelas deixadas de fora da análise (estágios, práticas e atividades científico culturais). Importa esclarecer, então, que aspectos do ofício, relativos ao saber historiográfico, são privilegiados por tais percursos.

Com esse objetivo, consideramos as atividades curriculares voltadas para o Saber Historiográfico em cinco dimensões. Percebemos que uma parte das atividades curriculares é ocupada com o diálogo com outras disciplinas, a esta parte denominamos de Atividades Interdisciplinares. Outra parte é voltada para a abordagem de períodos, espaços ou agentes, 
por meio das quais se tem acesso às análises acumuladas pela disciplina. Esta parte foi identificada por Atividades Historiográficas. Notamos que algumas atividades curriculares se voltam para os estudos de teoria e metodologia, de modo que as reunimos sob a categoria Atividades Teórico-metodológicas. Um grupo de atividades estão comprometidas com as competências necessárias à realização de pesquisas acerca do passado e foram agregadas na categoria Atividades de Pesquisa. Por fim, constatamos que algumas atividades estão direcionadas para o desenvolvimento de competências do ofício, como o trato com acervos, narrativas, correntes historiográficas etc., as quais foram juntadas na categoria Atividades de Competências do Ofício.

A seguir, apontamos como tais dimensões se apresentam nos cursos analisados.

\begin{tabular}{|c|c|c|c|c|c|c|c|c|}
\hline \multirow{4}{*}{ Instituição } & \multicolumn{7}{|c|}{ Dimensões do SABER HiSTORIOGRÁFiCO } & \\
\hline & \multirow{3}{*}{$\begin{array}{l}\text { Carga } \\
\text { Horária } \\
\text { Total }\end{array}$} & \multirow{2}{*}{\multicolumn{2}{|c|}{$\begin{array}{c}\text { Carga Horária } \\
\text { Saber } \\
\text { Historiográfico }\end{array}$}} & \multicolumn{5}{|c|}{$\begin{array}{c}\text { Atividades Curriculares } \\
(\%)\end{array}$} \\
\hline & & & & \multirow{2}{*}{$\begin{array}{l}\text { Interd } \\
\text { iscipli } \\
\text { nares }\end{array}$} & \multirow{2}{*}{$\begin{array}{l}\text { Histor } \\
\text { iográf } \\
\text { icas }\end{array}$} & \multirow{2}{*}{$\begin{array}{l}\text { Teóric } \\
\text { o/ } \\
\text { Metod } \\
\text { ológic } \\
\text { as }\end{array}$} & \multirow{2}{*}{$\begin{array}{l}\text { Pesqu } \\
\text { isa }\end{array}$} & \multirow{2}{*}{$\begin{array}{l}\text { Comp } \\
\text { lemen } \\
\text { tares }\end{array}$} \\
\hline & & $(\%)$ & (horas) & & & & & \\
\hline $1 \mathrm{CO}$ & 3268 & 59,12 & 1932 & 3,11 & 67,08 & 14,29 & 12,42 & 3,11 \\
\hline $1 \mathrm{NE}$ & 2800 & 48,00 & 1344 & 4,76 & 71,43 & 23,81 & - & - \\
\hline $2 \mathrm{NE}$ & 2985 & 55,28 & 1650 & 3,64 & 76,36 & 14,55 & 5,45 & - \\
\hline $3 \mathrm{NE}$ & 2830 & 47,70 & 1350 & 4,44 & 73,33 & 8,89 & 8,89 & 4,44 \\
\hline $4 \mathrm{NE}$ & 2865 & 61,78 & 1770 & 10,17 & 69,49 & 13,56 & 3,39 & 3,39 \\
\hline $1 \mathrm{~N}$ & 2865 & 48,17 & 1380 & - & 78,26 & 13,04 & 8,70 & - \\
\hline $2 \mathrm{~N}$ & 2860 & 58,74 & 1680 & 7,14 & 50,00 & 17,86 & 10,71 & 14,29 \\
\hline $3 \mathrm{~N}$ & 3420 & 57,02 & 1950 & 6,15 & 69,23 & 6,15 & 9,23 & 9,23 \\
\hline $1 \mathrm{SE}$ & 3300 & 40,00 & 1320 & 13,64 & 50,00 & 18,18 & 13,64 & 4,55 \\
\hline $2 \mathrm{SE}$ & 2805 & 42,78 & 1200 & 5,00 & 65,00 & 15,00 & - & 15,00 \\
\hline $3 \mathrm{SE}$ & 3240 & 50,00 & 1620 & 3,70 & 62,96 & 11,11 & 18,52 & 3,70 \\
\hline $1 \mathrm{~S}$ & 3366 & 45,99 & 1548 & 15,69 & 54,90 & 11,76 & 13,73 & 3,92 \\
\hline $2 \mathrm{~S}$ & 2880 & 54,17 & 1560 & 7,69 & 69,23 & 11,54 & 11,54 & - \\
\hline
\end{tabular}

Fonte: quadro elaborado pelos autores, 2016

O quadro acima está assim organizado: na primeira coluna, as instituições; na segunda a carga horária total dos cursos; a segunda e a terceira colunas apontam o percentual da carga horária total voltada para o Saber Historiográfico e o quanto ele representa em horas; o grupo de colunas reunidas em Atividades Curriculares especifica a distribuição da carga horária apontada na terceira e quarta colunas, conforme os grupos de atividades e sua relação com a 
formação pretendida.

O quadro acima deixa claro que a maior parte da carga horária destinada ao Saber Historiográfico volta-se para aquelas atividades curriculares identificadas pelos alunos como disciplinas de conteúdo - aquelas que dão conta do passado. Trata-se na verdade, das disciplinas que seguem tanto a tradição na disciplina no Ocidente quanto sua conformação no Brasil. ${ }^{21}$ As atividades voltadas para os domínios da historiografia, identificadas na coluna denominada «Historiográficas», ocupam pelo menos cinquenta por cento da carga horária voltada para o Saber Historiográfico, de modo que sopesá-las é fundamental. Daí nossa preocupação em perceber como esse volume de atividades vem sendo operado pelos cursos de formação.

Voltamo-nos, então, para as atividades curriculares identificadas com o domínio da historiografia, as quais compreendem a eixo estruturante da dimensão Saber Historiográfico. Aqui, mais uma vez, ocupamo-nos com as regularidades. Vamos ao quadro seguinte, no qual categorizamos as abordagens que compõem o eixo principal do Saber Historiográfico, as atividades de cunho historiográfico, ocupadas com a apresentação, debate, discussão e problematização da produção de conhecimento histórico, segundo os recortes estabelecidos pela tradição da disciplina. Assim, identificamos sete grupos de atividades.

Em primeiro lugar, aquelas ocupadas com a abordagem da trajetória brasileira. Nesse grupo reunimos as atividades curriculares que dão conta da História do Brasil, preponderantemente pensadas em termos cronológicos - a periodização segue a tradição, distinguindo a Colonização Portuguesa, o Império, a República Velha, a Era Vargas e o Tempo Presente. Em seguida, as atividades curriculares que se destinam à abordagem da trajetória ocidental, desde a periodização tradicional, tal como foi pensada no século XIX História Antiga, Medieval, Moderna e Contemporânea. Aqui, encontra-se o eixo dos cursos analisados, posto que nenhum outro saber, nenhuma outra abordagem assume o mesmo espaço ou a mesma importância, em termos de carga horária alocada. Outro grupo é formado pelas disciplinas que tratam das histórias locais. Nelas, estudam-se os temas relativos aos lugares de memória eleitos pela tradição local. ${ }^{22}$ Dois conjuntos de atividades almejam cumprir as exigências estabelecidas pelas leis $10.639 / 03$ e $11.645 / 08,{ }^{23}$ compreendendo a História da África e a História Indígena. Nenhum dos dois conjuntos de atividades é atendido

\footnotetext{
${ }^{21}$ Para o caso brasileiro ver FERREIRA, Marieta de Moraes (2012).

${ }^{22}$ LE GOFF, Jacques (1994).

23 BRASIL. Lei n. 10.639, de 9 de janeiro de 2003. Altera a Lei n. 9.394, de 20 de dezembro de 1996. Lei $\mathrm{n}^{\mathbf{0}}$ 11.645, de 10 de Março de 2008. Altera a Lei no 9.394, de 20 de dezembro de 1996, modificada pela Lei no 10.639 , de 9 de janeiro de 2003.
} 
por todas as instituições da amostra. A trajetória americana, ao contrário está presente em todos os cursos analisados, constituindo o penúltimo conjunto de atividades. Mais uma vez, a perspectiva cronológica é determinante. Por fim, um conjunto de atividades aborda temas e problemas diversos, provavelmente em função da capacidade instalada de cada curso - neste conjunto estão desde disciplinas de tópicos temáticos, quando outras voltadas para as compreensões de sujeitos, enfoques e perspectivas analíticas.

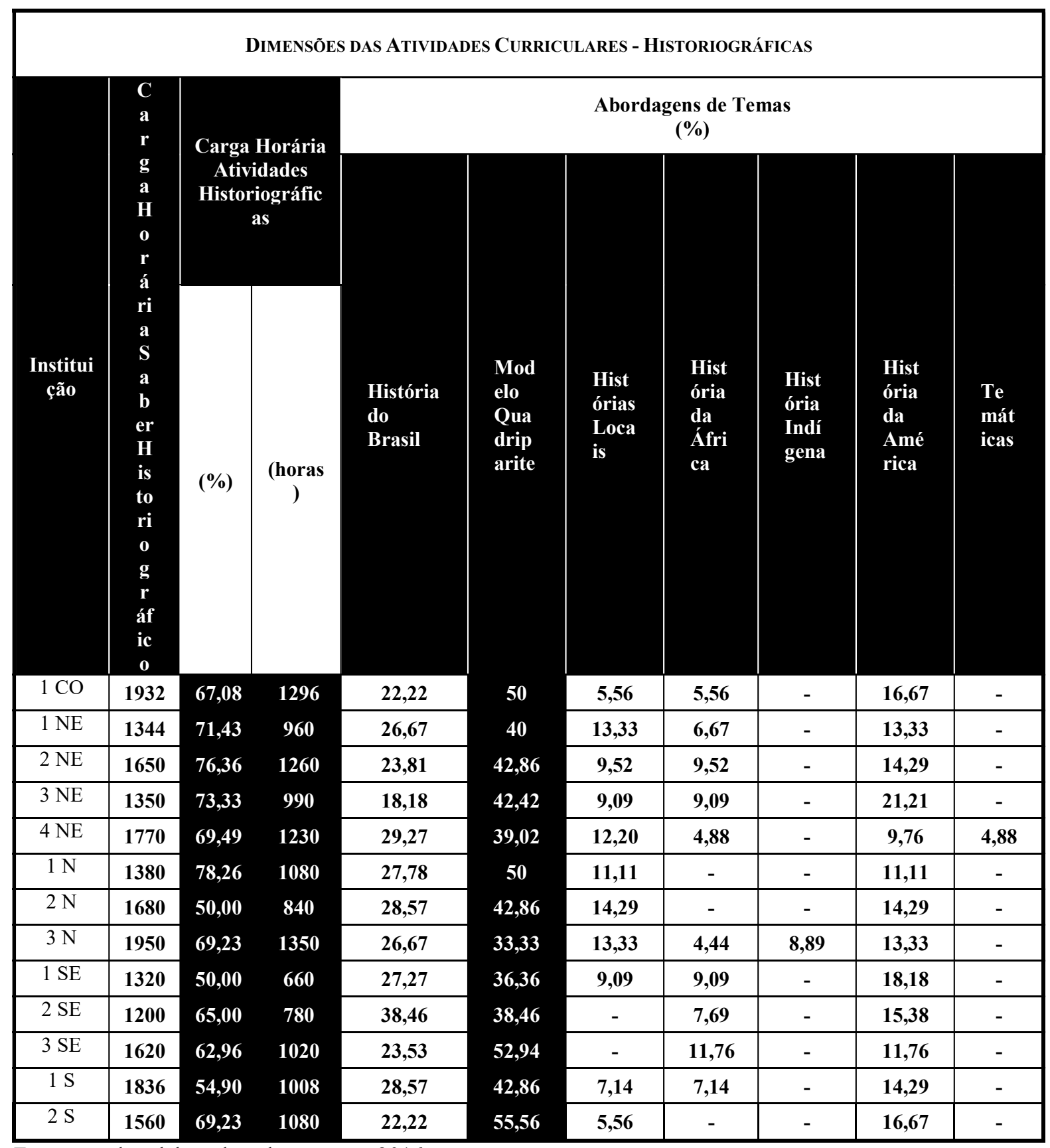

Fonte: quadro elaborado pelos autores, 2016

O modelo quadripartite, como se vê, é preponderante. Ele acaba por conformar o eixo 
do que os cursos delineiam como a formação do Historiador, indicando, direta ou indiretamente, perspectivas, enfoques e as hierarquias subjacentes aos campos de investigação do conhecimento histórico.

Vejamos, agora, o saber docente. Conforme apontamos páginas atrás, o Saber Docente ocupa espaço mínimo nos percursos de formação. ${ }^{24}$ Não obstante, ainda que o espaço de formação seja diminuto, ele expressa uma perspectiva acerca da docência e da relação mantida com o saber de referência. As atividades curriculares constituem um caminho para perceber ambas questões. Consideramos que para melhor entende-las era necessário distinguir dois aspectos do saber docente, conforme adiantamos páginas atrás: o saber sobre ensinar e o saber sobre o aluno. Notemos, inicialmente, como tal distinção se dá nos percursos analisados.

No quadro seguinte, indicamos a relação do Saber Docente com a carga horária total dos cursos. Distinguimos, ainda, o percentual de cada uma das dimensões do saber docente o saber sobre ensinar e o saber sobre o aluno, conforme reflexão apontada anteriormente.

\begin{tabular}{|c|c|c|c|c|c|}
\hline \multirow[b]{3}{*}{ Instituição } & \multicolumn{4}{|c|}{ DisTRIBUIÇÃo DA CARGA HoRÁRIA - SABER DOCENTE } & \\
\hline & \multicolumn{3}{|c|}{ Relação com o Percurso } & \multicolumn{2}{|c|}{ Distinção } \\
\hline & $\begin{array}{c}\text { Carga } \\
\text { Horária } \\
\text { Total }\end{array}$ & Percentual & $\begin{array}{c}\text { Carga } \\
\text { Horária } \\
\text { Relativa }\end{array}$ & $\begin{array}{c}\text { Saber do } \\
\text { Ensino } \\
(\%)\end{array}$ & $\begin{array}{c}\text { Saber do Aluno } \\
(\%)\end{array}$ \\
\hline $1 \mathrm{CO}$ & 3268 & 22,52 & 736 & 18,48 & 4,04 \\
\hline $1 \mathrm{NE}$ & 2800 & 9,14 & 256 & 6,86 & 2,29 \\
\hline $2 \mathrm{NE}$ & 2985 & 12,06 & 360 & 8,04 & 4,02 \\
\hline $3 \mathrm{NE}$ & 2830 & 23,85 & 675 & 18,55 & 5,30 \\
\hline $4 \mathrm{NE}$ & 2865 & 10,47 & 300 & 4,19 & 6,28 \\
\hline $1 \mathrm{~N}$ & 2865 & 6,81 & 195 & 6,81 & - \\
\hline $2 \mathrm{~N}$ & 2860 & 6,29 & 180 & 6,29 & - \\
\hline $3 \mathrm{~N}$ & 3420 & 8,77 & 300 & 7,02 & 1,75 \\
\hline $1 \mathrm{SE}$ & 3300 & 11,36 & 375 & 9,55 & 1,82 \\
\hline $2 \mathrm{SE}$ & 2805 & 8,56 & 240 & 6,42 & 2,14 \\
\hline $3 \mathrm{SE}$ & 3240 & 0,92 & 30 & - & 0,92 \\
\hline $1 \mathrm{~S}$ & 3366 & 16,04 & 540 & 13,90 & 2,14 \\
\hline $2 \mathrm{~S}$ & 2880 & 9,37 & 270 & 8,33 & 1,04 \\
\hline
\end{tabular}

Fonte: quadro elaborado pelos autores, 2016

Por meio do quadro, notamos, inicialmente, a importância dispensada ao Ensino nos

${ }^{24}$ Conforme o quadro «Atividades Teórico-Científicas Obrigatórias - Saber Historiográfico e Saber Docente. 
cursos analisados. Dos treze cursos considerados, em sete a carga horária voltada para o Saber Docente não alcança dez por cento da carga horária total do curso. Em outros três cursos, ela não perfaz quinze por cento do total do tempo de formação e em outros três ela não compreende vinte e cinco por cento. Em seguida, fica claro que o Saber Docente é entendido, preponderantemente, como saber sobre como ensinar. O aluno aparece como uma preocupação remota, quase residual.

Nosso movimento seguinte foi perscrutar as atividades curriculares que compõem o Saber Docente, conforme a distinção estabelecida. Vejamos os quadros.

\begin{tabular}{|c|c|c|c|c|c|c|c|c|c|}
\hline \multirow{4}{*}{ Instituição } & \multicolumn{8}{|c|}{ Dimensões do Saber Docente - Ensino } & \\
\hline & \multirow{3}{*}{$\begin{array}{c}\text { Carga } \\
\text { Horária } \\
\text { Total }\end{array}$} & \multirow{2}{*}{\multicolumn{2}{|c|}{$\begin{array}{l}\text { Carga Horária } \\
\text { Saber Ensinar }\end{array}$}} & \multicolumn{6}{|c|}{$\begin{array}{c}\text { Atividades Curriculares } \\
(\%)\end{array}$} \\
\hline & & & & \multirow{2}{*}{$\begin{array}{l}\text { Antr } \\
\text { opol } \\
\text { ogia } \\
\text { da } \\
\text { Edu } \\
\text { caçã } \\
\text { o }\end{array}$} & \multirow{2}{*}{$\begin{array}{l}\text { Filos } \\
\text { ofia } \\
\text { da } \\
\text { Edu } \\
\text { caçã } \\
\text { o }\end{array}$} & \multirow{2}{*}{$\begin{array}{l}\text { Psic } \\
\text { ologi } \\
\text { a da } \\
\text { Edu } \\
\text { caçã } \\
\text { o }\end{array}$} & \multirow{2}{*}{$\begin{array}{l}\text { Legi } \\
\text { slaç } \\
\text { ão }\end{array}$} & \multirow{2}{*}{$\begin{array}{l}\text { Did } \\
\text { átic } \\
\text { a }\end{array}$} & \multirow{2}{*}{$\begin{array}{l}\text { Com } \\
\text { petê } \\
\text { ncias }\end{array}$} \\
\hline & & $(\%)$ & (horas) & & & & & & \\
\hline $1 \mathrm{CO}$ & 3268 & 18,48 & 604 & - & 21,85 & - & 11,92 & 11,92 & 54,30 \\
\hline $1 \mathrm{NE}$ & 2800 & 6,86 & 192 & - & 33,33 & - & 33,33 & 33,33 & - \\
\hline $2 \mathrm{NE}$ & 2985 & 8,04 & 240 & - & 50,00 & - & 25,00 & 25,00 & - \\
\hline $3 \mathrm{NE}$ & 2830 & 18,55 & 525 & - & 11,43 & - & 22,86 & 57,14 & 8,57 \\
\hline $4 \mathrm{NE}$ & 2865 & 4,19 & 120 & - & - & - & 50,00 & 50,00 & - \\
\hline $1 \mathrm{~N}$ & 2865 & 6,81 & 195 & - & - & 38,46 & - & 61,54 & - \\
\hline $2 \mathrm{~N}$ & 2860 & 6,29 & 180 & - & - & 33,33 & 33,33 & 33,33 & - \\
\hline $3 \mathrm{~N}$ & 3420 & 7,02 & 240 & - & 25,00 & - & - & 75,00 & - \\
\hline $1 \mathrm{SE}$ & 3300 & $\mathbf{9 , 5 5}$ & 315 & - & 19,05 & 19,05 & 19,05 & 42,86 & - \\
\hline $2 \mathrm{SE}$ & 2805 & 6,42 & 180 & 33,33 & 33,33 & 33,33 & - & - & - \\
\hline $3 \mathrm{SE}$ & 3240 & - & - & - & - & - & - & - & - \\
\hline $1 \mathrm{~S}$ & 3366 & 13,90 & 468 & - & 15,38 & - & 30,77 & 53,85 & - \\
\hline $2 \mathrm{~S}$ & 2880 & 8,33 & 240 & - & - & 12,50 & 25,00 & 25,00 & 37,50 \\
\hline
\end{tabular}

Fonte: quadro elaborado pelos autores, 2016

Os percursos curriculares analisados sugerem que a discussão relativa ao Ensino é perpassada, em muitos dos cursos de formação, por uma instrumentalização do futuro professor para o exercício da docência. A preponderância de atividades curriculares voltadas para Didática, Legislação Educacional e Filosofia da Educação em quase todos os percursos em referência, quando associada ao domínio absoluto do saber de referência, sugere que os saberes sobre o ensino são percebidos como uma ferramenta de apoio, não como princípios epistemológicos. Saber ensinar, nesta perspectiva, compreende o domínio de certos 
princípios, mas, sobretudo, dos procedimentos que permitem a "tradução" do saber de referência para os estudantes da Educação Básica em fases diversas de amadurecimento cognitivo.

Isto fica ainda mais evidente ao considerarmos a atenção que tais percursos reservam aos alunos da Educação Básica, sujeitos de direitos da Educação, objetivo último da formação em Licenciatura.

\begin{tabular}{|c|c|c|c|c|c|}
\hline \multirow{4}{*}{ Instituição } & \multicolumn{5}{|c|}{ Dimensões do SABer Docente - Aluno } \\
\hline & \multirow{3}{*}{$\begin{array}{c}\text { Carga } \\
\text { Horária } \\
\text { Total }\end{array}$} & \multirow{2}{*}{\multicolumn{2}{|c|}{$\begin{array}{c}\text { Carga Horária } \\
\text { Saber sobre o Aluno }\end{array}$}} & \multicolumn{2}{|c|}{$\begin{array}{c}\text { Atividades Curriculares } \\
\qquad(\%)\end{array}$} \\
\hline & & & & \multirow{2}{*}{$\begin{array}{l}\text { Psicologia da } \\
\text { Infância e da } \\
\text { Adolescência }\end{array}$} & \multirow{2}{*}{ Inclusão (LIBRAS) } \\
\hline & & $(\%)$ & (horas) & & \\
\hline $1 \mathrm{CO}$ & 3268 & 4,04 & 132 & 54,55 & 45,45 \\
\hline $1 \mathrm{NE}$ & 2800 & 2,29 & 64 & 100,00 & - \\
\hline $2 \mathrm{NE}$ & 2985 & 4,02 & 120 & 50,00 & 50,00 \\
\hline $3 \mathrm{NE}$ & 2830 & 5,30 & 150 & 60,00 & 40,00 \\
\hline $4 \mathrm{NE}$ & 2865 & 6,28 & 180 & 66,67 & 33,33 \\
\hline $1 \mathrm{~N}$ & 2865 & - & 0 & - & - \\
\hline $2 \mathrm{~N}$ & 2860 & - & $\mathbf{0}$ & - & - \\
\hline $3 \mathrm{~N}$ & 3420 & 1,75 & 60 & 100,00 & - \\
\hline $1 \mathrm{SE}$ & 3300 & 1,82 & 60 & - & 100,00 \\
\hline $2 \mathrm{SE}$ & 2805 & 2,14 & 60 & - & 100,00 \\
\hline $3 \mathrm{SE}$ & 3240 & 0,93 & 30 & - & 100,00 \\
\hline $1 \mathrm{~S}$ & 3366 & 2,14 & 72 & 100,00 & - \\
\hline $2 \mathrm{~S}$ & 2880 & 1,04 & 30 & - & 100,00 \\
\hline
\end{tabular}

Fonte: quadro elaborado pelos autores, 2016

O espaço dispensado aos alunos, nos cursos de formação analisados, compreende, de um lado, a consideração dos estágios de amadurecimento, conforme as teorias do desenvolvimento cognitivo, e a necessidade da inclusão dos alunos com um tipo de deficiência do outro. As condições históricas da infância e da adolescência, os significados da escola para os estudantes do tempo presente, a forma como aprendem História e o significado que esta assume para eles, entre outros fatores, são deixados de fora. Mais uma vez, a sugestão, aqui, é de que para ensinar o saber de referência o fundamental é domina-lo - o que faz com que ele assuma um fim em si mesmo e não em relação ao tempo e aos agentes sociais por meio dos quais deveria adquirir sentido e relevância social. 


\section{(IN)CONCLUSÕES}

A Educação está em discussão no Brasil, nos tempos que correm. Incluem-se nas pautas dos debates acerca de um tema tão abrangente quanto necessário, os processos de formação de professores. Refletir sobre como eles se conformam, desde os cursos de licenciatura, atentando para o modo como encaminham as competências necessárias ao exercício da docência é, portanto, questão do momento. Neste texto, pretendemos participar do debate, por meio de um movimento inicial que sopesa, nos cursos de formação de professores de História, o espaço destinado a tais competências. Nesse sentido, o texto não é mais que um apontamento, indicando algumas notas acerca da questão de fundo dos cursos de formação de historiadores comprometidos com a docência.

O debate interessa a todos, pois tem desdobramentos em dimensões diversas. No Brasil, as discussões que envolvem a Escola frequentemente se dão sem leva-la em consideração. A Escola e seus agentes são percebidos como espaços de concretização de reflexões ocorridas alhures. Sintomático, neste sentido, é o espaço diminuto destinado à Escola e as suas questões nos cursos de formação aqui considerados. De todo modo, parecenos que a discussão deve partir de análises acerca dos rumos assumidos pelas Licenciaturas.

Nos casos que levamos em conta, neste texto, notamos que o Saber Docente não apenas cumpre função periférica nos processos de formação, como assumem um sentido meramente instrumental. Saber ensinar emerge como o domínio de técnicas e procedimentos que permitiriam a transformação do saber de referência em conhecimento acessível aos alunos. Estes, por sua vez, pouco interessam aos cursos cujos percursos curriculares estudamos. Em se tratando de formação histórica, causa estranheza, sobretudo, a falta de abordagens que considerem os alunos da Educação Básica como agentes do tempo em que estão inseridos. Seria irônico, se não fosse trágico, a ausência de perspectiva histórica no trato com os estudantes da Educação Básica nos cursos de formação de professores de História.

Importa não esquecer que os percursos curriculares são, em larga medida, resultado de escolhas. E estas dizem muito do que pensamos e do que queremos. Que o debate continue.

\section{REFERÊNCIAS}

ALMEIDA, José Luis Vieira; TREVISO, Vanessa Cristina. O conhecimento em Jean Piaget e a educação escolar. Cadernos de Educação: Ensino e Sociedade, Ano 1, n. 1, p. 233-244, 2014.

Disponível em: http://unifafibe.com.br/revistasonline/arquivos/cadernodeeducacao/sumario/31/040420140745 44.pdf. Acesso em: 23 fev. 2019. 
BOCHNIAK, Regina. Questionar o conhecimento - Interdisciplinaridade na escola. São Paulo: Loyola, 1992.

BORGES, Cecília. Saberes docentes: diferentes tipologias e classificações de um campo de pesquisa. Educação \& Sociedade, Ano XXII, n. 74, p. 59-76, abr. 2001. Disponível em: http://www.scielo.br/pdf/es/v22n74/a05v2274.pdf. Acesso em: 23 fev. 2019.

BRASIL. Conselho Nacional de Educação. Conselho Pleno. Resolução N.1, de 18 de fevereiro de 2002. Institui Diretrizes Curriculares Nacionais para a Formação de Professores da Educação Básica, em Nível Superior, Curso de Licenciatura, de Graduação Plena. Brasília: MEC, 2002. Disponível em: http://portal.mec.gov.br/cne/arquivos/pdf/rcp01_02.pdf. Acesso em: 28 set. 2016.

Conselho Nacional de Educação. Conselho Pleno. Resolução N.2, de 19 de fevereiro de 2002. Institui a Duração e a Carga Horária Dos Cursos de Licenciatura, de Graduação Plena, de Formação de Professores da Educação Básica em Nível Superior. Brasília: $\quad 2002 . \quad$ DEC, Disponível http://portal.mec.gov.br/cne/arquivos/pdf/CP022002.pdf. Acesso em: 28 set. 2016.

Conselho Nacional de Educação. Conselho Pleno. Resolução CNE/ CP N. 2, de 01 de julho de 2015. Define as Diretrizes Curriculares Nacionais para a formação inicial em nível superior (cursos de licenciatura, cursos de formação pedagógica para graduados e cursos de segunda licenciatura) e para a formação continuada. Brasília: MEC, 2015. Disponível em: http://pronacampo.mec.gov.br/images/pdf/res_cne_cp_02_03072015.pdf. Acesso em: 28 set. 2016.

Decreto N. 5.159, de 28 de julho de 2004. Aprova a Estrutura Regimental e o Quadro Demonstrativo dos Cargos em Comissão e das Funções Gratificadas do Ministério da Educação, e dá outras providências. Brasília: MEC, 2004. Disponível em: http://portal.mec.gov.br/arquivos/pdf/d5159.pdf. Acesso em: 23 fev. 2019.

. Lei N. 9.394, de 20 de dezembro de 1996. Diário Oficial da União, Brasília, DF, 23 de dezembro de 1996. Disponível em: <http://www.planalto.gov.br/ccivil_03/LEIS/19394.htm>. Acesso em: 10 set. 2016.

Lei N. 10.639, de 9 de janeiro de 2003. Altera a Lei N. 9.394, de 20 de dezembro de 1996, que estabelece as diretrizes e bases da educação nacional, para incluir no currículo oficial da Rede de Ensino a obrigatoriedade da temática "História e Cultura Afro-Brasileira", e dá outras providências. Brasília: Congresso Nacional, 2003. Disponível em: http://www.planalto.gov.br/ccivil_03/LEIS/2003/L10.639.htm>. Acesso em: 10 set. 2016.

Lei N. 11.645, de 10 de março de 2008. Altera a Lei N. 9.394, de 20 de dezembro de 1996, modificada pela Lei no 10.639, de 9 de janeiro de 2003, que estabelece as diretrizes e bases da educação nacional, para incluir no currículo oficial da rede de ensino a obrigatoriedade da temática "História e Cultura Afro-Brasileira e Indígena". Disponível em: http://www.planalto.gov.br/ccivil_03/_Ato2007-2010/2008/Lei/L11645.htm>. Acesso em: 10 set. 2016.

CAIMI, Flávia Eloisa. Aprendendo a ser professor de História. Passo Fundo: Ediupf, 2008. 
Por que os alunos (não) aprendem História? Reflexões sobre ensino, aprendizagem e formação de professores de História. Tempo, v 11, n. 21, p. 17-32, jun. 2006. Disponível em: http://www.scielo.br/pdf/tem/v11n21/v11n21a03. Acesso em: 23 fev. 2019.

CARDOSO, Oldimar Pontes. Representações dos professores sobre saber histórico escolar. Cadernos de Pesquisa, v. 37, n. 130, p. 209-226, jan./abr. 2007. Disponível em: http://www.scielo.br/pdf/cp/v37n130/10.pdf. Acesso em: 23 fev. 2019.

CARDOZA, Isabela Fonseca. A sociedade pós-moderna e o fenômeno das tribos urbanas. Lato \& Sensu, v. 4, n. 1, p. 3-5, out. 2003.

CERTEAU, Michel de. A operação histórica. In: LE GOFF, Jacques; NORA, Pierre (dir.) História: novos problemas. Rio de Janeiro: Francisco Alves, 1984. p. 18-48.

COELHO Wilma de Nazaré Baía; COELHO, Mauro Cezar. História, historiografia e saber escolar: a educação para as relações étnico-raciais e o saber histórico na literatura didática. Espaço pedagógico, v. 21, n. 2, p.358-379, jul./dez. 2014. Disponível em: http://seer.upf.br/index.php/rep/article/view/4306. Acesso em: 23 fev. 2019.

COELHO, Mauro Cezar. A Escola e as Licenciaturas em História: discutindo as Diretrizes Curriculares para a Educação Básica (qual seu lugar nos cursos de formação de professores de História?). In: XIII ENCONTRO ESTADUAL DE HISTÓRIA DA ANPUH-RS: Ensino, Direitos e Democracia, 2016, Santa Cruz do Sul.

; COELHO, Wilma de Nazaré Baía. As licenciaturas em história e a lei 10.639/03: percursos de formação para o trato com a Diferença? Educação em Revista, v. 34, e192224, 2018. Disponível em: <http://www.scielo.br/pdf/edur/v34/1982-6621-edur-34-e192224.pdf>. Acesso em: 24 fev. 2019.

CUNHA, Olívia Maria Gomes da. Bonde do mal: notas sobre território, cor, violência e juventude numa favela do subúrbio carioca. In: REZENDE, Claudia Barcellos; MAGGIE, Yvonne. Raça como retórica: a construção da diferença. Rio de Janeiro: Civilização Brasileira, 2001. p. 83-153.

DAYRELL, Juarez. O rap e o funk na socialização da juventude. Educação e Pesquisa, v. 28, n. 1, p. 117-136, 2002. Disponível em: http://www.scielo.br/pdf/ep/v28n1/11660.pdf. Acesso em: 23 fev. 2019.

DOURADO, Luiz Fernandes. Diretrizes curriculares nacionais para a formação inicial e continuada dos profissionais do magistério da educação básica: concepções e desafios. Educação \& Sociedade, v. 36, n. 131, p. 299-324, abr./jun. 2015. Disponível em: $<$ http://www.scielo.br/pdf/es/v36n131/1678-4626-es-36-131-00299.pdf $>$. Acesso em: 04 jul. 2016.

FAZENDA, Ivani. Integração e Interdisciplinaridade no Ensino Brasileiro: efetividade ou ideologia? São Paulo: Loyola, 1992.

Interdisciplinaridade: história, teoria e pesquisa. 4 ed. Campinas: Papirus, 1999. FERREIRA, Marieta de Moraes. O ensino de história na Faculdade Nacional de Filosofia da Universidade do Brasil. História, Ciências, Saúde - Manguinhos, v. 19, n. 2, p. 611-636, 
abr./jun. 2012. Disponível em: www.scielo.br/pdf/hscm/v19n2/14.pdf. Acesso em: 23 set. 2016.

FRAGA, Dinora; SILVEIRA, Nádia Geisa. Interdisciplinaridade na sala de aula: uma experiência pedagógica nas terceiras e quartas séries do primeiro grau. Porto Alegre: Editora da Universidade/ UFGRS, 1995.

FURET, Francois. A oficina da história. Lisboa: Gradiva, [s.d.], p. 7-37.

GARBIN, Elisabete Maria. Cultur@s juvenis, identid@des e internet: questões atuais. Revista Brasileira de Educação, n. 23, p. 119-135, ago. 2003. Disponível em: http://www.scielo.br/pdf/rbedu/n23/n23a08.pdf. Acesso em: 23 fev. 2019.

GAUTHIER, Clermont et al. Por uma teoria da pedagogia: pesquisas contemporâneas sobre o saber docente. 2. ed. Ijuí: Editora Unijuí, 2006.

KEHL, Maria Rita. Radicais, raciais, racionais: a grande fratria do rap na periferia de São Paulo. São Paulo em Perspectiva, v. 13, n. 3, p. 96-106, 1999. Disponível em: http://www.scielo.br/pdf/spp/v13n3/v13n3a12.pdf. Acesso em: 23 fev. 2019.

LE GOFF, Jacques. História e Memória. Campinas, SP: Editora Unicamp, 1994.

História. Documento/Monumento. In: História e Memória. Campinas: Editora da UNICAMP, 1996. p. 17-166 e 535-549.

LIMA, Ari. Funkeiros, timbaleiros e pagodeiros: notas sobre juventude e música negra na cidade de Salvador. Cadernos Cedes, v. 22, n. 57, p. 77-96, ago. 2002. Disponível em: http:// www.scielo.br/pdf/ccedes/v22n57/12004.pdf. Acesso em: 23 fev. 2019.

MAGRO, Viviane Melo de Mendonça. Adolescentes como autores de si próprios: cotidiano, educação e o hip-hop. Cadernos Cedes, v. 22, n. 57, p. 63-75, ago. 2002. Disponível em: http://www.scielo.br/pdf/ccedes/v22n57/12003.pdf. Acesso em: 23 fev. 2019.

MONTEIRO, Ana Maria Ferreira da Costa. Professores de História: entre saberes e práticas. Rio de Janeiro: Mauad X, 2007.

PERRENOUD, Philippe. Dez novas competências para ensinar. Artmed, 2000.

PIAGET, Jean. Seis Estudos de Psicologia. Rio de Janeiro: Editora Forense, 1980. .; INHELDER, Barbel. A psicologia da criança. Rio de Janeiro: Ed.Bertrand Brasil, 1994.

TARDIF, Maurice. Saberes docentes e formação profissional. 4. ed. Rio de Janeiro: Vozes, 2002.

VALDEMARIN, Vera Teresa. O discurso pedagógico como forma de transmissão do conhecimento. Cadernos Cedes, v. 19, n. 44, p. 73-84, abr. 1998. Disponível em: http:/www.scielo.br/scielo.php?script=sci_abstract\&pid=S0101-

$32621998000100007 \& \operatorname{lng}=$ en\&nrm=iso\&tlng=pt. Acesso em: 23 fev. 2019. 
VYGOTSKY, Liev Semiónovitch. A Formação Social da Mente. São Paulo: Martins Fontes, 2007.

Pensamento e Linguagem. Tradução Jefferson Luiz Camargo. Revisão técnica José Cipolla Neto. São Paulo: Martins Fontes, 2008.

WERNECK, Vera Rudge. Sobre o processo de construção do conhecimento: o papel do ensino e da pesquisa. Ensaio: avaliação de políticas públicas educacionais, v. 14, n. 51, p. 173-196, abr./jun. 2006.

Disponível

em:

http://www.scielo.br/pdf/ensaio/v14n51/a03v1451.pdf. Acesso em: 17 out. 2016.

Recebido em 24.02.2019

Aprovado em 11.04.2019 